\title{
Effectiveness of the Wheat Blast Resistance Gene Rmg8 in Bangladesh Suggested by Distribution of an AVR-Rmg8 Allele in the Pyricularia oryzae Population
}

\author{
Jemal Tola Horo, Soichiro Asuke, Trinh Thi Phuong Vy, and Yukio Tosa ${ }^{\dagger}$
}

Graduate School of Agricultural Science, Kobe University, Kobe 657-8501, Japan

Accepted for publication 5 June 2020.

\begin{abstract}
Wheat blast caused by the Triticum pathotype of Pyricularia oryzae was first reported in 1985 in Brazil and recently spread to Bangladesh. We tested whether Rmg8 and RmgGR119, recently identified resistance genes, were effective against Bangladeshi isolates of the pathogen. Common wheat accessions carrying Rmg 8 alone (IL191) or both $R m g 8$ and $R m g G R 119$ (GR119) were inoculated with Brazilian isolates ( $\mathrm{Br} 48$, $\mathrm{Br}$, and $\mathrm{Br} 116.5)$ and Bangladeshi isolates (T-108 and T-109). Br48, T-108, and T-109 carried the eI type of AVR-Rmg 8 (the avirulence gene corresponding to $R m g 8$ ) while $\mathrm{Br} 5$ and $\mathrm{Br} 116.5$ carried its variants, eII

was reduced to a low level against the eII/eII' carriers. A survey of databases and sequence analyses revealed that all Bangladeshi isolates carried the eI type which induced a higher level of resistance than the eII/eII' types. The resistance of IL191 (Rmg8/-) to the eI carriers was maintained even at the heading stage and at the higher temperature. In addition, GR119 (Rmg8/RmgGR119) displayed higher levels of resistance than IL191 at this stage. These results suggest that Rmg8 combined with $R m g G R 119$ will be useful in breeding for resistance against wheat blast in Bangladesh.
\end{abstract} and eII' types, respectively. Detached primary leaves of IL191 and GR119 were resistant to all isolates at $25^{\circ} \mathrm{C}$. At a higher temperature $\left(28^{\circ} \mathrm{C}\right)$, their resistance was still effective against the eI carriers but
Keywords: avirulence gene, Bangladesh, genetics and resistance, Pyricularia oryzae, resistance gene, wheat blast
Wheat blast caused by the Triticum pathotype (MoT) (Cruz and Valent 2017) of Pyricularia oryzae (Zhang et al. 2016) is one of the most destructive wheat diseases in South America and Asia. This disease was first observed in 1985 in Brazil (Urashima et al. 1993), then spread to adjacent countries such as Bolivia (in 1996), Paraguay (in 2002), and Argentina (in 2011), causing significant yield losses (Ceresini et al. 2018). In 2016, an outbreak of wheat blast occurred in Bangladesh (Callaway 2016; Islam et al. 2016; Malaker et al. 2016) and affected $15 \%$ of the country's total wheat area (Malaker et al. 2016). This was the first report of a wheat blast epidemic in a country other than in South America. The inoculum for this outbreak in Bangladesh was considered to originate from South America (Islam et al. 2016; Malaker et al. 2016).

Breeding for resistance is the most economic and labor-saving method for disease control. In the past 30 years, efforts have been made to breed wheat cultivars with improved blast resistance. Cruz et al. (2016) found that a 2NS chromosomal fragment derived from Aegilops ventricosa conferred resistance to head blast. Recently, BARI Gom33, a new wheat cultivar carrying the 2NS fragment was released in Bangladesh (Mottaleb et al. 2019). However, the

†Corresponding author: Y. Tosa; tosayuki@kobe-u.ac.jp

Funding: This research was supported by Grants-in-aid for scientific research from the Japan Society for the Promotion of Science (17H01462), and a grant, "International collaborative research project for solving global issues", from Agriculture, Forestry and Fisheries Research Council Secretariat, Ministry of Agriculture, Forestry and Fisheries (MAFF), Japan.

First and second authors contributed equally to this work.

*The $e$-Xtra logo stands for "electronic extra" and indicates there are supplementary materials published online.

The author(s) declare no conflict of interest.

(c) 2020 The American Phytopathological Society resistance conferred by the $2 \mathrm{NS}$ fragment is not effective in some genetic backgrounds or against some fungal strains (Cruz et al. 2016). As such, it is crucial to identify new resistance genes against the wheat blast fungus.

Resistance genes against wheat blast must be effective at high temperatures and at the heading stage of the plant, as wheat blast is a spike disease that is favored by high temperature. We have identified five resistance genes against the wheat blast fungus, i.e., Rmg 2 and Rmg3 (Zhan et al. 2008), Rmg7 (Tagle et al. 2015), $R m g 8$ (Anh et al. 2015), and RmgGR119 (Wang et al. 2018). Among these, $R m g 2$ and $R m g 3$, identified in common wheat, were temperature sensitive and not effective against spike infection. $R m g 7$, identified in emmer wheat, was effective against spike infection but not effective at high temperature. On the other hand, $R m g 8$, identified in common wheat cultivar S-615, was effective at both seedling and heading stages and at relatively high temperature (Anh et al. 2015; Wang et al. 2018). Recently, Wang et al. (2018) identified a new resistance gene, RmgGR119, in common wheat accession GR 119 and proved that Rmg 8 combined with $R m g G R 119$ conferred strong resistance to Triticum isolates collected in Brazil.

The final goal for breeders is to develop a cultivar with broadspectrum and durable resistance. In this context, the spectrum and durability of a resistance gene may be evaluated on the basis of distribution and stability of its corresponding avirulence gene (Tosa and Chuma 2014). Anh et al. (2018) cloned AVR-Rmg8, an avirulence gene corresponding to $R m g 8$, and found that it was recognized not only by $R m g 8$ but also by $R m g 7$ (Anh et al. 2018). Wang et al. (2018) analyzed nucleotide sequences of AVR-Rmg8 homologs in Triticum isolates collected in Brazil and observed that it was divided into three types, eI, eII, and eII'.

In this study, we examined whether Rmg 8 and $\operatorname{RmgGR} 119$ were effective against Bangladeshi isolates of $P$. oryzae. Infection assays coupled with analyses of the avirulence gene suggest that Rmg8, and probably $R m g G R 119$, are effective against wheat blast in Bangladesh. 


\section{MATERIALS AND METHODS}

Fungal materials. Fungal materials used in the study comprised 11 Triticum isolates (isolates from Triticum spp. or isolates of the Triticum pathotype) of P. oryzae. Eight of these isolates (Supplementary Table S1) were collected in Bangladesh in 2016-17 and provided by Md Tofazzal Islam, Bangabandhu Sheikh Mujibur Rahman Agricultural University (BSMRAU), Bangladesh, while another three isolates $(\mathrm{Br} 48, \mathrm{Br} 5$, and $\mathrm{Br} 116.5)$ were collected in Brazil in 1990-92 (Wang et al. 2018). Br48 4 A8_d6, an $A V R-R m g 8$ disruptant of $\mathrm{Br} 48$ produced by Wang et al. (2018), was used as a recipient of $A V R-R m g 8$ homologs.

Plant materials. T. aestivum accession IL191 was selected as a representative of 18 different cultivar/accessions that carry $R m g 8$ alone (Wang et al. 2018) as it displayed the highest resistance among them at the seedling stage. T. aestivum accession GR119, carrying both Rmg8 and RmgGR 119 (Wang et al. 2018), and cultivar Hope, carrying no resistance gene, were also employed in the study.

Seedling infection assay. Wheat seeds were sown in vermiculite supplied with liquid fertilizer in a seedling case and grown in a controlled-environment room with a 12 -h photoperiod of fluorescent lighting at $22^{\circ} \mathrm{C}$. Primary leaves of 8-day-old seedlings were fixed onto a hard-plastic board using rubber bands immediately prior to inoculation. In the case of detached leaf inoculations, seedlings were grown in vermiculite in a controlledenvironment room as described above for 8 days or in soil (Sakata Prime Mix, Sakata Seeds Corporation, Yokohama, Japan) in a greenhouse $\left(18\right.$ to $26^{\circ} \mathrm{C}$ ) for 17 days. The primary leaves of the 8 day-old seedlings were used for initial evaluations of resistance/ susceptibility while the third leaves of the 17-day-old seedlings were used for precise evaluations of the degree of resistance. Leaves were cut at the base, inserted into Eppendorf tubes $(2 \mathrm{ml})$ containing distilled water, and fixed onto a hard-plastic board.

Fungal isolates/strains were grown on oatmeal agar media (5 g of sucrose, $40 \mathrm{~g}$ of oat meal, and agar at $20 \mathrm{~g} /$ liter) for 7 days. Aerial mycelia from the 7-day-old cultures were removed by rubbing the mycelial surfaces with cotton balls. The cultures were incubated further under blue light to induce sporulation. Three to four days later, conidia were harvested and a suspension $\left(1 \times 10^{5}\right.$ conidia $\left./ \mathrm{ml}\right)$ containing $0.01 \%$ Tween 20 was evenly sprayed onto fixed leaves using an air compressor. Inoculated leaves were placed in a humid tray and incubated in the dark at 25 and $28^{\circ} \mathrm{C}$. After $24 \mathrm{~h}$, they were transferred to dry conditions with a 12-h photoperiod and further incubated at 25 and $28^{\circ} \mathrm{C}$ for 3 to 4 days. Infection types were recorded based on the size and color of lesions. The size was rated on six progressive grades from 0 to 5 : $0=$ no visible infection; $1=$ pinhead spots; $2=$ small lesions $(<1.5 \mathrm{~mm}) ; 3=$ scattered lesions of intermediate size $(<3 \mathrm{~mm}) ; 4=$ large lesion; and $5=$ complete shriveling of leaf blades. The color was designated as B for brown and $\mathrm{G}$ for green. A disease score (infection type) was composed of a number denoting the lesion size and a letter indicating the lesion color. For example, infection type 1B indicated brown pinhead spots. Infection types $0,1 \mathrm{~B}$, and $2 \mathrm{~B}$ were considered resistant (avirulent) while infection types 3G, 4G, and 5G were considered susceptible (virulent). Intermediate types, 3B and 3BG, were categorized as resistant because the browning of leaf tissues in these types had been shown to be caused by hypersensitive reactions (HR) (Hyon et al. 2012). In infection assays with primary leaves,

TABLE 1. Primers used in this study

\begin{tabular}{ll}
\hline Name & \multicolumn{1}{c}{ Sequence $\left(5^{\prime} \rightarrow 3^{\prime}\right)$} \\
\hline A8_ORF_Seq_F & TCTAGTTGCATTTTCTCACTCCA \\
A8_ORF_Seq_R & GGCCGTTTAACGTTTTTGG \\
AVR-Rmg8_multi_cloning_F & ATAAAAGCAATACGGTCGGA \\
AVR-Rmg8_multi_cloning_R & CACGTATAATTACGTTCTGTGTG \\
AVR-Rmg8_F2 & ACCGCATCGGCTTTTTCTT \\
AVR-Rmg8_R2 & TGCCTTCTAGTACCGGGAAGT \\
\hline
\end{tabular}

infection types $4 \mathrm{~B}$ and 5B were observed in some isolate/cultivar combinations. They were also categorized as resistant because the blighting or shriveling of whole leaves in these types had been shown to be caused by extensive HR (Murakami et al. 2000). Four leaves were employed for each cultivar/isolate combination in one replication. The infection assays with primary leaves and third leaves were replicated three times and twice, respectively.

Spike infection assay. Test plants were grown for 4 to 5 months in a field or greenhouse. At the stage of full head emergence (before flowering), a stem with a spike was cut at the base, trimmed to $\sim 50 \mathrm{~cm}$ (including the spike), and put into a test tube $(150 \mathrm{~mm}$ in length and $10 \mathrm{~mm}$ in diameter) with water containing antibiotics (MISAKI solution for cut flowers, OAT Agrio, Tokyo, Japan). The spikes were inoculated with conidial suspension $\left(1.5 \times 10^{5}\right.$ conidia/ $\mathrm{ml}$ ), covered with a black plastic bag, and incubated in the dark at 25 and $28^{\circ} \mathrm{C}$. After $24 \mathrm{~h}$, the plastic bag was removed, and the spikes were incubated further under a 12-h photoperiod at the same temperature as in the dark. Seven to eight days postinoculation, infection was rated with six progressive grades from 0 to 5: $0=$ no visible infection; 1 = brown pinhead spots; 2 = brown lesions of intermediate size $(<3 \mathrm{~mm}) ; 3=$ large lesions surrounded by brown tissues; 4 = extensive necrosis or chlorosis; and $5=$ complete blighting of the spike. Infection types of 0 to 3 were considered resistant, and 4 to 5 were considered susceptible. Two spikes were employed for each cultivar/isolate combination in one replication. The infection assay with spikes was repeated three times.

Extraction of fungal genomic DNA. P. oryzae strains were cultured in liquid medium ( $3 \mathrm{~g}$ of yeast extract, $3 \mathrm{~g}$ of casamino acid, and $5 \mathrm{~g}$ of sucrose/liter) in a 200-ml Erlenmeyer flask for 4 to 5 days. Genomic DNA was extracted from harvested mycelia using a modified version of a protocol described by Nakayashiki et al. (1999). In short, $1 \mathrm{~g}$ of a fungal sample (mycelial powder) in $1 \mathrm{ml}$ of DNA extraction buffer $(100 \mathrm{mM} \mathrm{LiCl}, 100 \mathrm{mM}$ EDTA, $10 \mathrm{mM}$ Tris$\mathrm{HCl}, \mathrm{pH} 7.5$, and $0.5 \%$ sodium dodecyl sulfate) was incubated in a water bath at $65^{\circ} \mathrm{C}$ for $1 \mathrm{~h}$. After centrifuging at $15,000 \mathrm{rpm}$, the supernatant was applied to PCI (phenol/chloroform/isoamyl alcohol $=25: 24: 1$ ) to remove protein, and then to $1 \mathrm{ml}$ of isopropanol to precipitate DNA. After removing RNA with $1 \mu \mathrm{l}$ of RNase, DNA was precipitated, washed with ethanol, and resuspended in $25 \mu \mathrm{l}$ of TE.

Sequencing of $\boldsymbol{A V R}$ - Rmg 8 homologs. A 550-bp fragment containing AVR-Rmg8 was amplified from genomic DNA of Bangladeshi isolates of $P$. oryzae with primers A8_ORF_Seq_F

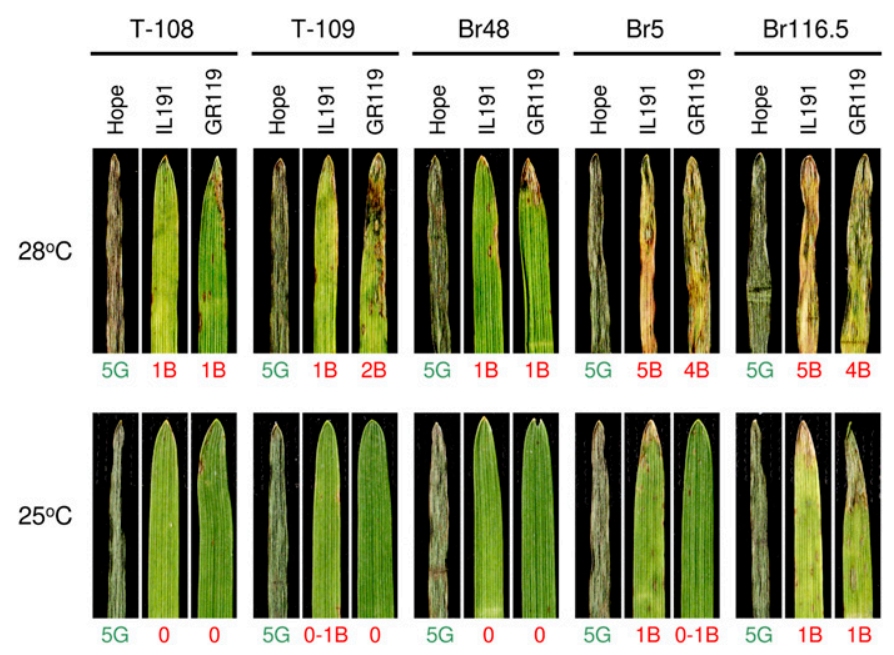

Fig. 1. Reactions of detached primary leaves of Hope (-/-), IL191 (Rmg8/-), and GR119 (Rmg8/RmgGR119) to Pyricularia oryzae isolates from Bangladesh (T-108 and T-109) and Brazil (Br48, Br5, and Br116.5) at 25 and $28^{\circ} \mathrm{C}, 5$ days after inoculation. Infection types are shown in red (resistant) or green (susceptible) under each picture. The assay was repeated three times with similar results. Results of the third replication are shown. 
and A8_ORF_Seq_R (Table 1). PCR products were checked by electrophoresis on a $0.7 \%$ agarose gel, purified by ethanol precipitation, and then sequenced using the ABI BigDye Terminator v3.1 Cycle Sequencing Kit (Applied Biosystems, Foster City, CA) and the ABI 3100 Genetic Analyzer following the manufacturer's instructions. Obtained nucleotide sequences were aligned with published sequences of eI (in Br48), eII (in Br5), and eII' (in
Br116.5) types of $A V R-R m g 8$ and those in databases (Supplementary Table S2). Based on these nucleotide sequences, maximum likelihood tree was constructed using the MEGA7 software (Kumar et al. 2016). Bootstrap values were generated from 1,000 replications.

Transformation of $P$. oryzae with $A V R-R m g 8$ homologs. A 1.8 -kb fragment containing the $A V R-R m g 8$ ORF, together with a

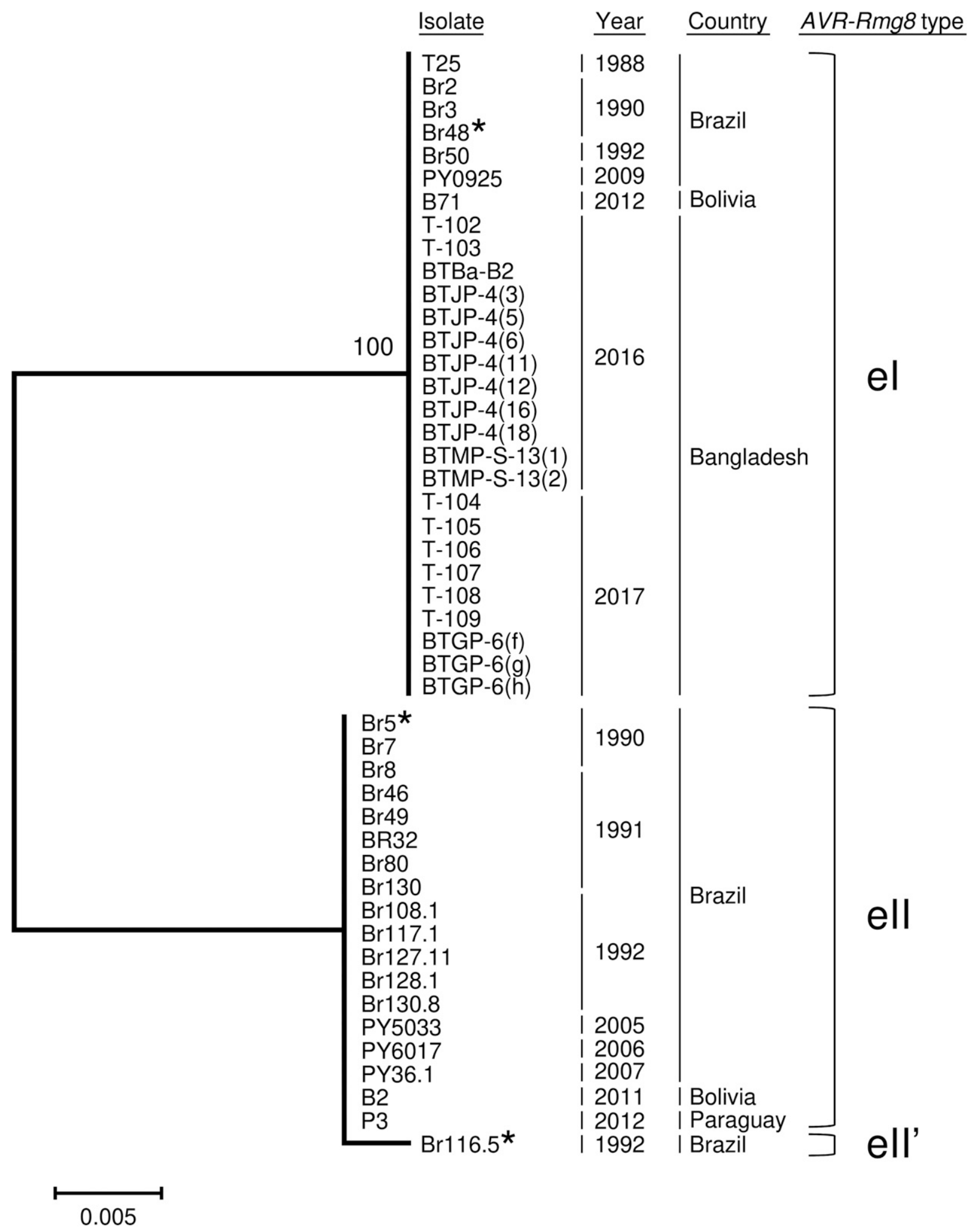

Fig. 2. Relationship of AVR-Rmg8 homologs in Triticum isolates used in this study and in databases. The dendrogram was constructed based on the nucleotide sequences of $A V R-R m g 8$ open reading frames using the maximum likelihood method. The number at the node represents a percentage of 1,000 bootstrap replicates. The scale bar represents 0.005 base substitutions per site. Asterisks indicate the three representative isolates. 
1,000-bp upstream region and a 500-bp downstream region, was amplified from $\mathrm{Br} 48$ (carrying the eI type), Br5 (carrying the eII type), and Br116.5 (carrying the eII' type) using AVR-Rmg8_ multi_cloning_F and AVR-Rmg8_multi_cloning_R primers (Table 1) and KOD-Plus-Neo polymerase (Toyobo, Osaka, Japan). The thermal cycler setup comprised $94^{\circ} \mathrm{C}$ for $2 \mathrm{~min}$, and 35 cycles of $94^{\circ} \mathrm{C}$ for $30 \mathrm{~s}, 60^{\circ} \mathrm{C}$ for $30 \mathrm{~s}$, and $68^{\circ} \mathrm{C}$ for $2 \mathrm{~min}$. The amplicon was run on a $2 \%$ agarose gel and extracted from the gel using QIAEX II Gel Extraction Kit (QIAGEN, Hilden, Germany). The purified fragment was ligated with pBluescriptII SK(+) digested with EcoRV and introduced into Escherichia coli DH5- $\alpha$. The recombinant plasmids were introduced into $\mathrm{Br} 48 \Delta \mathrm{A} 8$ _d6 following the PEG-mediated cotransformation protocol (Tosa et al. 2005) with pII99 (carrying a geneticin resistance gene) (Namiki et al. 2001) as a selection marker. Positive colonies were selected on media containing G418 sulfate and confirmed by PCR using the primers mentioned above.

Southern blot analysis of transformants. Genomic DNAs of Br48, Br48 $\triangle \mathrm{A} 8$ _d6, and transformants were digested with EcoRI (Takara, Kusatsu, Japan), electrophoresed on a $0.7 \%$ agarose gel in the TBE buffer, and transferred to a nylon membrane (Hybond-N+, GE Healthcare, Buckinghamshire, England) through capillary blotting. The DNA fragments were fixed to a membrane by UV

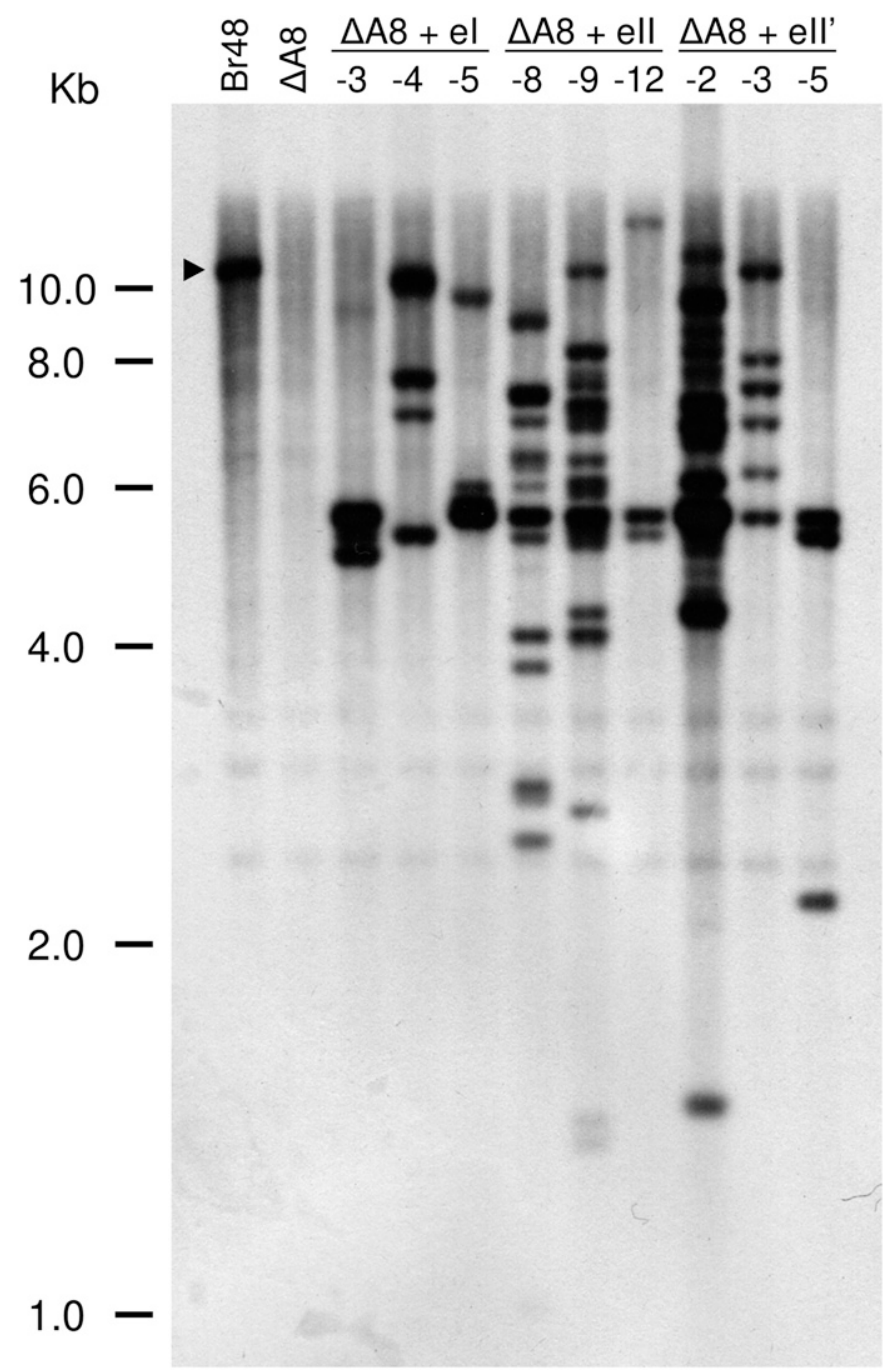

Fig. 3. Southern blot analysis of $\mathrm{Br} 48, \mathrm{Br} 48 \Delta \mathrm{A} 8(\triangle \mathrm{A} 8)$, and its transformants carrying the eI type $(\Delta \mathrm{A} 8+\mathrm{eI}-3,4$, and 5$)$, eII type $(\Delta \mathrm{A} 8+\mathrm{eII}-8,9$, and 12$)$, and eII' type ( $\triangle \mathrm{A} 8+\mathrm{eII}$ ' $-2,3$, and 5) of $A V R-R m g 8$ isolated from $\mathrm{Br} 48, \mathrm{Br} 5$, and $\mathrm{Br} 116.5$, respectively. A fragment containing the endogenous $A V R-R m g 8$ in $\mathrm{Br} 48$ is indicated by a triangle. radiation. A 322-bp AVR-Rmg8 fragment amplified from the genomic DNA of Br48 with primers, AVR-Rmg8_F2 and AVRRmg8_R2 (Table 1), was labeled following the instruction of the ECL Direct Nucleic Acid Labeling and Detection System (GE Healthcare). The membrane was hybridized for $12 \mathrm{~h}$ with the labeled probe in the Gold hybridization buffer (GE Healthcare) at $42^{\circ} \mathrm{C}$. After hybridization, the membrane was washed twice in the primary washing buffer $(0.4 \%$ sodium dodecyl sulfate and $0.5 \times$ $\mathrm{SSC}$ ) for $10 \mathrm{~min}$ at $55^{\circ} \mathrm{C}$, and then twice in $2 \times \mathrm{SSC}$ for $5 \mathrm{~min}$ at room temperature. Signals were detected following the manufacturer's instructions.

\section{RESULTS}

Infection assay at the seedling stage. In a preliminary experiment, intact primary leaves of Hope (-/-), IL191 (Rmg8/-), and GR119 (Rmg8/RmgGR119) were inoculated with the eight Bangladeshi isolates of $P$. oryzae and incubated at 25 and $28^{\circ} \mathrm{C}$. IL191 and GR119 were resistant to all Bangladeshi isolates at both temperature (Supplementary Table S1). We chose T-108 and T-109 as representatives of the Bangladeshi isolates for further analyses.

When the two Bangladeshi isolates and three representative Brazilian isolates of $P$. oryzae $(\mathrm{Br} 48, \mathrm{Br} 5$, and $\mathrm{Br} 116.5)$ were sprayed on detached primary leaves of the three wheat lines, these isolates were divided into two groups, group A (T-108, T-109, and $\mathrm{Br} 48)$ and group $\mathrm{B}(\mathrm{Br} 5$ and $\mathrm{Br} 116.5)$. At $25^{\circ} \mathrm{C}$, group A was almost completely avirulent on IL191 and GR119 while group B produced some brown flecks (Fig. 1). At $28^{\circ} \mathrm{C}$, group A was still avirulent on IL191 and GR119 while group B caused leaf shriveling (Fig. 1). It should be noted that these shriveled leaves were accompanied by tissue browning (infection types 5B and 4B-resistant reactions) in contrast to shriveled leaves of Hope (infection type $5 \mathrm{G}$-susceptible reactions).

Nucleotide sequences of $A V R-R m g 8$ in various isolates. $\mathrm{Br} 48$ in group A carries the eI type $A V R-R m g 8$ while $\mathrm{Br} 5$ and Br116.5 in group B carry its variants (the eII and eII' types) (Wang et al. 2018). To determine $A V R-R m g 8$ types of Bangladeshi isolates, an $A V R-R m g 8$ region ( $550 \mathrm{bp}$ ) was amplified from genomic DNA of the eight Bangladeshi isolates and sequenced. Nucleotide sequences of $A V R-R m g 8$ in these isolates were aligned with those from databases and literatures (Supplementary Table S2). A dendrogram showed that AVR-Rmg 8 in Triticum isolates worldwide was divided into two groups, eI and eII/eII' (Fig. 2). Isolates from South America harbored all the three types whereas Bangladeshi isolates harbored the eI type alone. The nucleotide sequences of the eI type in Bangladeshi isolates were $100 \%$ identical to the eI type in Br48.

Function of the three types of $A V R-R m g 8$ as avirulence genes. To clarify the association of the $A V R-R m g 8$ types with the phenotypes directly, $1.8 \mathrm{~kb}$ fragments containing the eI, eII, and eII'

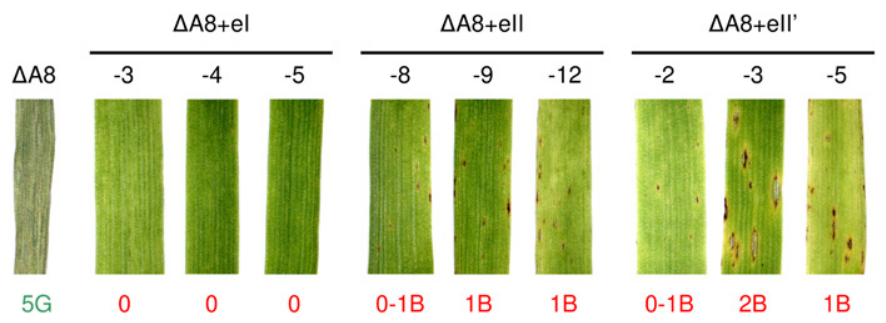

Fig. 4. Reactions of detached third leaves of IL191 (Rmg8/-) at $28^{\circ} \mathrm{C}$ to $\mathrm{Br} 48 \Delta \mathrm{A} 8(\Delta \mathrm{A} 8)$ and its transformants carrying the eI type $(\triangle \mathrm{A} 8+\mathrm{eI}-3,4$, and 5 ), eII type ( $\triangle \mathrm{A} 8+\mathrm{eII}-8,9$, and 12$)$, and eII' type ( $\triangle \mathrm{A} 8+\mathrm{eII} '-2,3$, and 5$)$ of $A V R$-Rmg 8 isolated from $\mathrm{Br} 48, \mathrm{Br} 5$, and $\mathrm{Br} 116.5$, respectively, 4 days after inoculation. Infection types are shown in red (resistant) or green (susceptible) under each picture. The assay was repeated twice with similar results. Results of the second replication are shown. 
types of $A V R-R m g 8$ were isolated from $\mathrm{Br} 48, \mathrm{Br} 5$, and $\mathrm{Br} 116.5$, respectively, and introduced into $\mathrm{Br} 48 \triangle \mathrm{A} 8$ _d6 (disruptant of $A V R$ Rmg8) which was virulent on both IL191 and Hope. Consequently, 11,14 , and 12 transformants were obtained from the transformation with the eI, eII, and eII' types, respectively. When sprayed on intact primary leaves of IL191 and Hope at room temperature $\left(\sim 22^{\circ} \mathrm{C}\right)$, six with the eI type $(\mathrm{Br} 48 \Delta \mathrm{A} 8+\mathrm{eI})$, six with the eII type

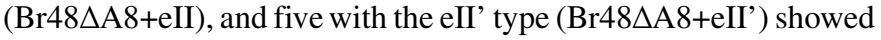
avirulence on IL191 (infection types 0 or 1B) without losing the high virulence on Hope (infection type 5G), indicating that all of these types are functional and recognized by $R m g 8$.

Three transformants were arbitrarily chosen as representatives from each of the three groups. The copy number of the transgenes in these transformants varied in each of $\mathrm{Br} 48 \Delta \mathrm{A} 8+\mathrm{eI}, \mathrm{Br} 48 \Delta \mathrm{A} 8+\mathrm{eII}$, and Br48 $\Delta \mathrm{A} 8+\mathrm{eII}$ ' (Fig. 3). Nevertheless, the three transformants in each group showed similar tendency in virulence on IL191; when they were sprayed on detached third leaves of IL191 and incubated at $28^{\circ} \mathrm{C}$, the eI transformants were completely avirulent while the eII and eII' transformants produced some brown spots or flecks (Fig. 4, Supplementary Fig. S1). These results suggest that the eI type induces a higher level of resistance than the eII/eII' types in Rmg8 carriers.

Spike infection assay. To evaluate the effect of Rmg 8 and RmgGR119 at the heading stage, spikes of Hope, IL191, and GR119 were inoculated with the representative Bangladeshi (T-108 and T-109) and Brazilian (Br48 and Br5) isolates of P. oryzae. IL191 was resistant to the eI carriers (T-108, T-109, and $\mathrm{Br} 48$ ) but susceptible to the eII carrier (Br5) (Fig. 5). Infection assays with the transformants suggested that these contrastive reactions were attributed to the AVR-Rmg8 types they harbored (Supplementary Fig. S2). GR119 displayed higher levels of resistance than IL191 against T-109 and Br48 (Fig. 5). Furthermore, GR119 was resistant even against $\mathrm{Br} 5$ to which IL191 was susceptible.

\section{DISCUSSION}

Wang et al. (2018) reported three types of $A V R-R m g 8$, i.e., eI, eII, and eII', in Triticum isolates collected in Brazil in 1990 to 1992. In their infection assay with intact leaves at $25^{\circ} \mathrm{C}$, a correlation was not recognized between the $A V R-R m g 8$ types of these isolates and the
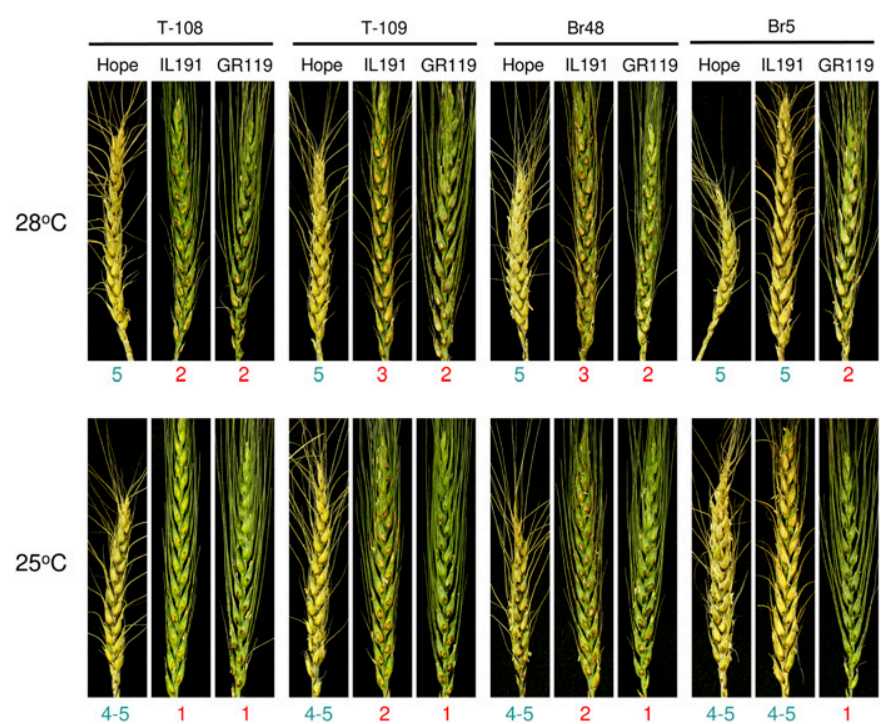

Fig. 5. Reactions of detached spikes of Hope (-/-), IL191 (Rmg8/-), and GR119 (Rmg8/RmgGR119) to Pyricularia oryzae isolates from Bangladesh (T-108 and T-109) and Brazil (Br48 and Br5) at 25 and $28^{\circ} \mathrm{C}, 7$ days after inoculation. Infection types are shown in red (resistant) or green (susceptible) under each picture. The assay was repeated three times with similar results. Results of the third replication are shown. degree of their avirulence on IL191 (carrying Rmg8). However, careful examination with detached leaves and spikes at 25 to $28^{\circ} \mathrm{C}$ revealed that group A carrying the eI type was highly avirulent on IL191 while group B carrying the eII/eII' types was more aggressive or virulent on this accession (Figs. 1 and 5). Infection assays with the transformants revealed that the eI type induced higher levels of resistance in comparison with the eII/eII' types in this $R m g 8$ carrier (Fig. 4, Supplementary Fig. S2). In contrast to the Brazilian isolates, Bangladeshi isolates harbored the eI type with no exception (Fig. 2). The wheat blast population in Bangladesh is considered to be clonally derived from a single strain of one mating type (Cruz and Valent 2017), and therefore, is inferred to be composed of eI type carriers alone. These results suggest that $\operatorname{Rmg} 8$ will be effective against wheat blast in farmer's fields in Bangladesh.

GR119 carrying two genes (Rmg8/RmgGR119) displayed higher levels of resistance than IL191 ( $R m g 8 /-)$ against two of the three eI carriers tested at the heading stage (Fig. 5). In addition, GR119 was resistant even against the eII carrier to which IL191 was susceptible (Fig. 5). We suggest that the combination of Rmg8 with RmgGRI19 will make the resistance long-lasting in Bangladesh, and also may be effective in South America where both of the eI and eII/eII' types are prevailing (Fig. 2).

Wang et al. (2018) observed brown flecks on detached leaves of $\mathrm{S}-615$ inoculated with $\mathrm{Br} 48$ at $25^{\circ} \mathrm{C}$. On detached leaves of IL191 inoculated with the same isolate at $25^{\circ} \mathrm{C}$, however, no lesions were produced (Fig. 1). IL191 also showed similar immune responses against the other eI carriers at $25^{\circ} \mathrm{C}$ (Fig. 1). IL191 was selected as an accession displaying the highest level of resistance to $\mathrm{Br} 48$ at the seedling stage from the 18 lines carrying $R m g 8$ alone, i.e., cultivar S-615 and 17 accessions found by Wang et al. (2018). It is unlikely that IL191 carries another resistance gene because it is susceptible to Br48 AA8_d6, an AVR-Rmg8 disruptant of Br48 (Fig. 4). IL191 and S-615 seem to carry different $R m g 8$ alleles. For resistance breeding it is advisable to choose the most effective allele of $R m g 8$.

Jensen et al. (2019) reported that S-615 carrying Rmg8 was resistant to a Bangladesh isolate but susceptible to a Brazilian isolate. This Brazilian isolate may carry an $A V R-R m g 8$ allele other than the eI type. The current global population of the wheat blast fungus is composed of strains that differ with respect to virulence on $R m g 8$ (Fig. 2). Group A and group B are regarded as physiological races differentiated on an $R m g 8$ carrier although their difference becomes obvious only at high temperature or at the heading stage. When a system of race identification is constructed (Cruppe et al. 2020), therefore, an Rmg8 carrier should be included in the differential cultivars. It should be noted that this variation of $A V R$ $R m g 8$ was already present in the population of wheat blast isolates collected in Brazil in 1990 to 1992, only 5 to 7 years after the first detection of this fungus. This variation does not seem to be caused by an adaptation to $R m g 8$. Further studies are needed to clarify the process of evolution of $A V R-R m g 8$.

\section{ACKNOWLEDGMENTS}

We thank Md Tofazzal Islam, Bangabandhu Sheikh Mujibur Rahman Agricultural University, Bangladesh, for providing the wheat blast isolates collected in Bangladesh.

\section{LITERATURE CITED}

Anh, V. L., Anh, N. T., Tagle, A. G., Vy, T. T. P., Inoue, Y., Takumi, S., Chuma, I., and Tosa, Y. 2015. Rmg8, a new gene for resistance to Triticum isolates of Pyricularia oryzae in hexaploid wheat. Phytopathology 105: 1568-1572.

Anh, V. L., Inoue, Y., Asuke, S., Vy, T. T. P., Anh, N. T., Wang, S., Chuma, I., and Tosa, Y. 2018. Rmg8 and $R m g$ 7, wheat genes for resistance to the wheat blast fungus, recognize the same avirulence gene AVR-Rmg8. Mol. Plant Pathol. 19:1252-1256.

Callaway, E. 2016. Devastating wheat fungus appears in Asia for first time. Nature 532:421-422. 
Ceresini, P. C., Castroagudín, V. L., Rodrigues, F. Á., Rios, J. A., Aucique-Pérez, C. E., Moreira, S. I., Alves, E., Croll, D., and Maciel, J. L. N. 2018. Wheat blast: Past, present, and future. Annu. Rev. Phytopathol. 56:427-456.

Cruppe, G., Cruz, C. D., Peterson, G., Pedley, K., Asif, M., Fritz, A., Calderon, L., da Silva, C. L., Todd, T., Kuhnem, P., Singh, P. K., Singh, R. P., Braun, H.-J., Barma, N. C. D., and Valent, B. 2020. Novel sources of wheat head blast resistance in modern breeding lines and wheat wild relatives. Plant Dis. 104:35-43.

Cruz, C. D., Peterson, G. L., Bockus, W. W., Kankanala, P., Dubcovsky, J., Jordan, K. W., Akhunov, E., Chumley, F., Baldelomar, F. D., and Valent, B. 2016. The 2NS translocation from Aegilops ventricosa confers resistance to the Triticum pathotype of Magnaporthe oryzae. Crop Sci. 56:990-1000.

Cruz, C. D., and Valent, B. 2017. Wheat blast disease: Danger on the move. Trop. Plant Pathol. 42:210-222.

Hyon, G.-S., Nga, N. T. T., Chuma, I., Inoue, Y., Asano, H., Murata, N., Kusaba, M., and Tosa, Y. 2012. Characterization of interactions between barley and various host-specific subgroups of Magnaporthe oryzae and M. grisea. J. Gen. Plant Pathol. 78:237-246.

Islam, M. T., Croll, D., Gladieux, P., Soanes, D. M., Persoons, A., Bhattacharjee, P., Hossain, M. S., Gupta, D. R., Rahman, M. M., Mahboob, M. G., Cook, N., Salam, M. U., Surovy, M. Z., Sancho, V. B., Maciel, J. L. N., Nhani, A., Jr., Castroagudín, V. L., de Assis Reges, J. T., Ceresini, P. C., Ravel, S., Kellner, R., Fournier, E., Tharreau, D., Lebrun, M.-H., McDonald, B. A., Stitt, T., Swan, D., Talbot, N. J., Saunders, D. G. O., Win, J., and Kamoun, S. 2016. Emergence of wheat blast in Bangladesh was caused by a South American lineage of Magnaporthe oryzae. BMC Biol. $14: 84$.

Jensen, C., Tosa, Y., Islam, M. T., Talbot, N. J., Kamoun, S., and Saunders, D. G. O. 2019. Rmg8 confers resistance to the Bangladeshi lineage of the wheat blast fungus. Zenodo. https://doi.org/10.5281/zenodo.2574196

Kumar, S., Stecher, G., and Tamura, K. 2016. MEGA7: Molecular evolutionary genetics analysis version 7.0 for bigger datasets. Mol. Biol. Evol. 33:1870-1874.

Malaker, P. K., Barma, N. C. D., Tiwari, T. P., Collis, W. J., Duveiller, E., Singh, P. K., Joshi, A. K., Singh, R. P., Braun, H.-J., Peterson, G. L., Pedley, K. F., Farman, M. L., and Valent, B. 2016. First report of wheat blast caused by Magnaporthe oryzae pathotype triticum in Bangladesh. Plant Dis. 100: 2330.
Mottaleb, K. A., Govindan, V., Singh, P. K., Sonder, K., He, X., Singh, R. P., Joshi, A. K., Barma, N. C. D., Kruseman, G., and Erenstein, O. 2019. Economic benefits of blast-resistant biofortified wheat in Bangladesh: The case of BARI Gom 33. Crop Prot. 123:45-58.

Murakami, J., Tosa, Y., Kataoka, T., Tomita, R., Kawasaki, J., Chuma, I., Sesumi, Y., Kusaba, M., Nakayashiki, H., and Mayama, S. 2000. Analysis of host species specificity of Magnaporthe grisea toward wheat using a genetic cross between isolates from wheat and foxtail millet. Phytopathology 90:1060-1067.

Nakayashiki, H., Kiyotomi, K., Tosa, Y., and Mayama, S. 1999. Transposition of the retrotransposon MAGGY in heterologous species of filamentous fungi. Genetics 153:693-703.

Namiki, F., Matsunaga, M., Okuda, M., Inoue, I., Nishi, K., Fujita, Y., and Tsuge, T. 2001. Mutation of an arginine biosynthesis gene causes reduced pathogenicity in Fusarium oxysporum f. sp. melonis. Mol. Plant-Microbe Interact. 14:580-584.

Tagle, A. G., Chuma, I., and Tosa, Y. 2015. Rmg7, a new gene for resistance to Triticum isolates of Pyricularia oryzae identified in tetraploid wheat. Phytopathology 105:495-499.

Tosa, Y., and Chuma, I. 2014. Classification and parasitic specialization of blast fungi. J. Gen. Plant Pathol. 80:202-209.

Tosa, Y., Osue, J., Eto, Y., Oh, H. S., Nakayashiki, H., Mayama, S., and Leong, S. A. 2005. Evolution of an avirulence gene, AVR1-CO39, concomitant with the evolution and differentiation of Magnaporthe oryzae. Mol. PlantMicrobe Interact. 18:1148-1160.

Urashima, A. S., Igarashi, S., and Kato, H. 1993. Host range, mating type, and fertility of Pyricularia grisea from wheat in Brazil. Plant Dis. 77: 1211-1216.

Wang, S., Asuke, S., Vy, T. T. P., Inoue, Y., Chuma, I., Win, J., Kato, K., and Tosa, Y. 2018. A new resistance gene in combination with Rmg8 confers strong resistance against Triticum isolates of Pyricularia oryzae in a common wheat landrace. Phytopathology 108:1299-1306.

Zhan, S. W., Mayama, S., and Tosa, Y. 2008. Identification of two genes for resistance to Triticum isolates of Magnaporthe oryzae in wheat. Genome 51:216-221.

Zhang, N., Luo, J., Rossman, A. Y., Aoki, T., Chuma, I., Crous, P. W., Dean, R., de Vries, R. P., Donofrio, N., Hyde, K. D., Lebrun, M.-H., Talbot, N. J., Tharreau, D., Tosa, Y., Valent, B., Wang, Z., and Xu, J.-R. 2016. Generic names in Magnaporthales. IMA Fungus 7:155-159. 